
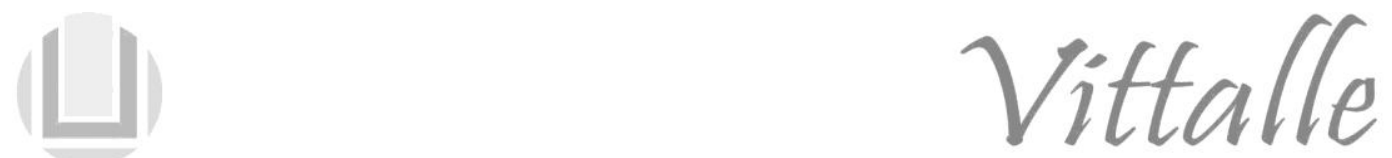

\title{
Artificial Intelligence technologies to manage obesity
}

\author{
Bruna Marmett $^{\mathrm{a}, 1,{ }^{*}}$, Roseana Böek Carvalho ${ }^{\mathrm{a}, 1}$, Melissa Santos Fortes ${ }^{\mathrm{b}, 2}$, \\ Sílvio César Cazella ${ }^{\mathrm{b}, 2}$
}

âLaboratório de Poluição Atmosférica - Universidade Federal de Ciências da Saúde de Porto Alegre, Porto Alegre, RS, Brazil

bUniversidade Federal de Ciências da Saúde de Porto Alegre, Porto Alegre, RS, Brasil

${ }^{1}$ Ambos primeiro autor

${ }^{2}$ Ambos segundo autor

\section{Histórico do Artigo \\ Recebido em: \\ $18 / 12 / 2017$ \\ Aceito em: \\ $08 / 03 / 2018$ \\ Key words: Obesity; Artificial intelligence; Body weight; Disease management.}

Palavras-chave: Obesidade; Inteligência artificial; Peso corporal; Manejo.

\begin{abstract}
In the last few decades, obesity has grown exponentially and it progression is imminent contributing to the increase of mortality levels. Artificial Intelligence (AI), which is Computer Science area, could be well applied to management of obesity, such as an important tool to avoid the threat caused by this disease. The aim of this literature review was to show AI applications to obesity management and discuss their effectiveness. The search was performed in the following databases: Public Medline (PubMed), Web of Science, Biblioteca Regional de Medicina (BIREME) and Google Academic, by using following keywords, "artificial intelligence" and "obesity". Our results led to some Artificial Intelligence systems used in obesity handling, which were: the Decision Support System to bariatric surgery patients; the MOPET app to motivate physical activity; Parameter Decreasing Methods and Artificial Neural Network to correlate obesity to cardiovascular disease; Artificial Neural Network to predict resting energy expenditure; a Neuro-Fuzzy Model to refine body mass index result; an Image Processing Algorithm; and a Support Vector Machine that monitors food intake. In this review, all investigated AI systems may have a tendency to more accurate results indicating a promising tool to manage obesity and related diseases.
\end{abstract}

\section{Tecnologias de Inteligência Artificial no manejo da obesidade}

\section{RESUMO}

Nas últimas décadas, a obesidade tem crescido de forma exponencial e essa progressão tem contribuído com o aumento dos níveis de mortalidade. Inteligência artificial, uma área da Ciência da Computação, poderia ter uma aplicação benéfica no manejo da obesidade, como uma ferramenta importante para evitar as ameaças à saúde causadas por essa condição. O objetivo desta revisão literária foi investigar as aplicações da AI no manejo da obesidade e discutir a sua eficácia. A busca foi realizada nas seguintes bases de dados: Public Medline (PubMed), Web of Science, Biblioteca Regional de Medicina (BIREME) e Google Academic; utilizando as palavras-chave "inteligência artificial" e "obesidade". Como resultado dessa revisão foi possível observar diferentes sistemas de AI empregados no tratamento da obesidade, os quais são: o "Decision Support System" para pacientes com cirurgia bariátrica; o "MOPET" aplicativo de atividade física; o "Parameter Decreasing Methods" e a "Artificial Neural Network" para correlacionar obesidade com doenças cardiovasculares; "Artificial Neural Network" para prever o gasto energético; a "Neuro-Fuzzy Model" para refinar os resultados fornecidos pelo IMC; um algoritmo para processamento de imagens; e o "Support Vector Machine", que monitora o consumo alimentar. Nesta revisão, todos os sistemas de AI apresentaram uma tendência a resultados com maior acurácia (mais precisos), indicando uma ferramenta promissora para o manejo da obesidade e das doenças relacionadas.

\section{Introduction}

Obesity is an epidemic disease associated with more morbidity than smoking, alcoholism and poverty, which affects approximately 500 million adults worldwide and considerably increases the risk of several other diseases; mainly cardiovascular, type 2

`Autor correspondente: brumarmett@hotmail.com (Marmett B.) 
diabetes; endocrine and metabolic disturbances; and certain types of cancer (1). In Brazil, the emerging urbanization and globalization leads to unfavorable shifts in diet and in physical activity, which consequently induce obesity development (1-4). This happens regardless of gender, age, ethinicity or social classes, and if it is not reversed, more than 1 billion adults are expected to be obese by 2030, turning into the leading cause of preventable death in the U.S (1-4).

In the past years, several studies have been developed involving Information Technology (IT), and more specifically, Artificial Intelligence (AI). This specific area of Computer Science is also a field in science and engineering and it has provided reasoning tools to support clinical decision-making for healthcare professionals (5-7). The foundations of AI are philosophy, mathematics, economics, neuroscience, psychology and computer engineering, being relevant to any intellectual task (7). As a wide definition, AI could be explained by making computers think and act humanly and rationally, doing things that originally people do better and performing functions that would be considered intelligent if made by a human being (7-10).

The application of AI in healthcare mainly includes techniques like: machine learning methods, such as the classical support vector machine, which classifies individuals into two groups through a decision boundary, and neural network that capture complex nonlinear relationships between input variables and an outcome; and the modern deep learning, as natural language processing, which comprises text processing and classification (11-13).

The higher obesity incidence, the lower population welfare. Therefore, a favorable scenario is established to the development of several diseases, the increase in hospital admissions and governmental costs. In its turn, AI shows an exponential evolution that can be used in favor of improving life quality (14). The major challenge to relate these two topics is to build up systems directly focus on prevention and treatment of obesity. These technologies need to be effective and accurate to management obese population (14).

There is limited literature about Artificial Intelligence and obesity handling. Therefore, the aim of this literature review is to introduce AI applications to obesity management and critically discuss their effectiveness in treating obesity.

\section{Methods}

In this study, we performed a literature review of AI and obesity management, during October and November of 2017, in the following databases: Public Medline (PubMed), Web of Science, Biblioteca Regional de Medicina (BIREME), and Google Scholar. The keywords used were "artificial intelligence" and "obesity". Inclusion criteria to select the articles were: 1) published between 2005 and 2017; 2) written in English; 3) directly related to clinical obesity management using an Artificial Intelligence system. Exclusion criteria were: 1) reviews; 2) in vitro or in vivo studies that used other animals than humans; 3) duplicated data; 4) patents; 5) applications to public health policies.

We performed a full text analyses in articles that fulfilled our criteria in order to identify the main outcomes. More detailed information on the selection process is in figure A.

\section{Results and Discussion}

The search found 54 articles (PubMed: 11, Web of Science: 15, BIREME: 32, Google Scholar: 1). Only 7 articles met the selection criteria (Figure 1). 
Vittalle - Revista de Ciências da Saúde v. 30, n. 2 (2018) 73-79

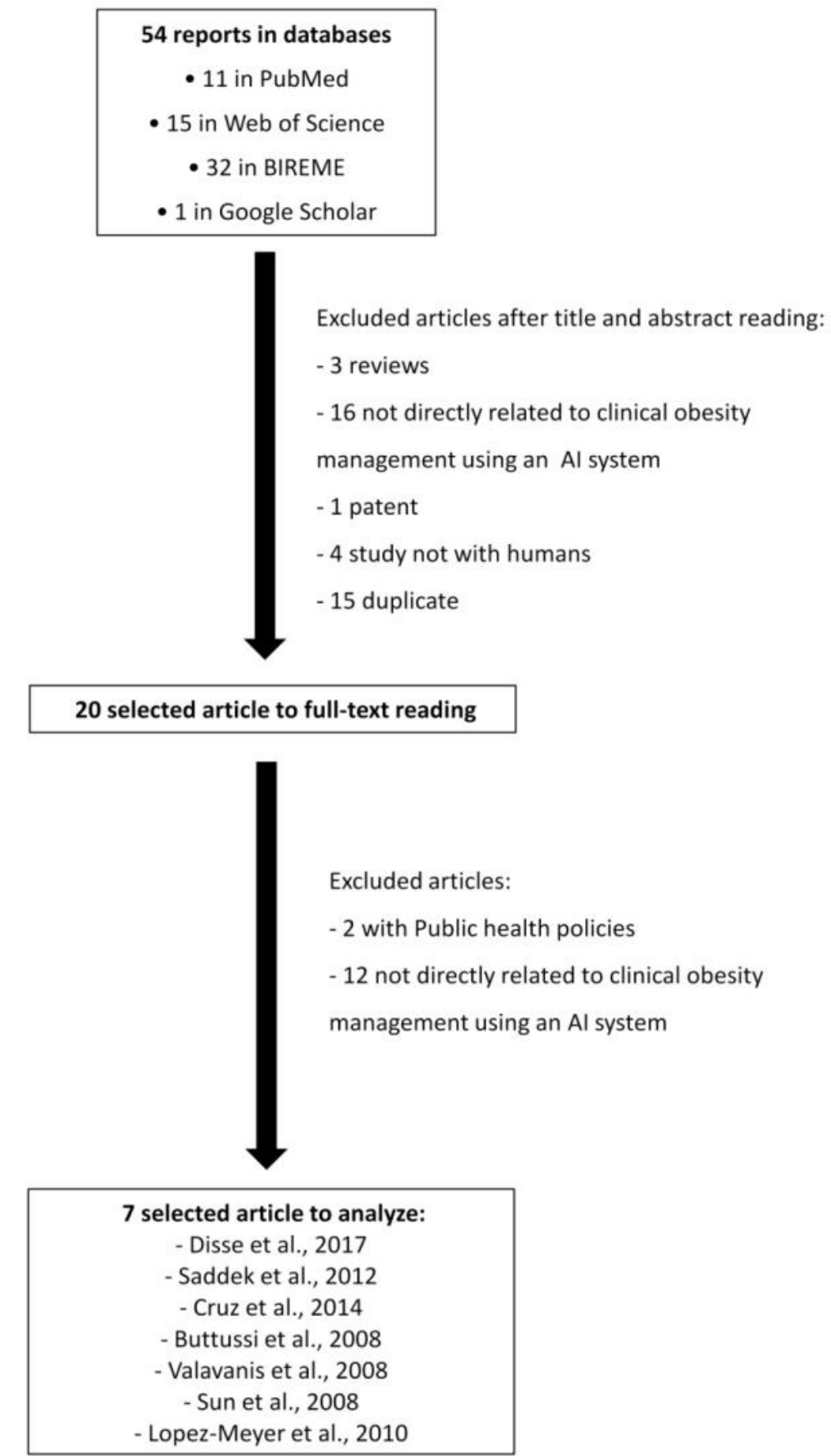

Figure 1: Selection article process.

Complex AI systems have been demonstrated to be an effective tool to help prevent, manage and treat obesity. For a new AI health system to be applied a Verification Methods Spectrum is required, which consists of the following steps: testing, run time monitoring, statistical analysis, model checking and theorem proving, organized by complexity levels, beginning with the simplest culminating with the most advanced (15).

A study performed by Cruz and colleagues (2014) validated a Decision Support System (DSS) based on a Bayesian Network to help in the nutritional diagnosis of bariatric surgery patients. The patients included in the study were submitted to the Roux-en-Y gastric bypass surgical technique. To build the database for the DSS scientific studies and consultations with nutrition specialists were carried out. The 
comparison between the diagnosis done by nutritionists, who were considered experts in the area (gold standard), and by the DSS demonstrated that all parameters evaluated by the system had higher sensibility and specificity. Emphasizing that some variables (deficiency of iron, vitamin B12 and thiamine) had a substantial disagreement among specialists, this fact was not found when the diagnosis was made by the system. The study concluded that DSS is a validated method to assist the health professional in the process of nutrition diagnosis of bariatric surgery patients (16).

The mobile application market, which includes several AI systems, has grown considerably over the past 5 years, and mobile applications (APPs) downloads reached 197 billion in $2017(17,18)$. Smartphones are interactive devices widely available nowadays, that can provide users with updating apps, including those related to health, which could be used to encourage behavioral changes $(19,20)$. Due to the increasing prevalence of obesity, physical inactivity and related diseases, information technology researchers and companies are giving particular attention to the development of wearable systems, like MOPET, seemed to motivate users to start and continue an exercise routine, which is considered a challenging activity (21). The system records the user heart rate and speed, thus allowing a good quality orientation based on the knowledge of sport physiologists and professional trainers. Regarding of real-time data, provided by sensors in the user, gives motivation in a safety guided exercise with an easy and practical layout. To update the system, the developers intend to improve some functions to personalize individual requirements trying to balance the user's needs and likes (21). There are many others apps focused on exercising that may help users with their routine, such as BunnyBolt, App-titude, iDAT (22-24). For the development of a successful app, technology creators need to balance health evidence and expert recommendation (20).

In studies focused on obesity co morbidities, cardiovascular disease (CVD) is one of the most cited worldwide health problem (4). Valavanis and colleagues (2008) created and applied in a group of 2341 participants a system based on the use of Parameter Decreasing Methods (PDM) and Artificial Neural Network (ANN) to identify variables related to the beginning of obesity status. In order to predict the risk of increasing body mass index (BMI) that leads to a higher risk to develop CVD, a combination of 32 variables, such as personal information about lifestyle containing nutritional habits and genetic profile was accessed. The application of the system resulted in an accuracy of $77,89 \%$ in the validation tests while BMI analyses had an accuracy of $69,15 \%$ in predict risk factor for CVD as an independent factor (25). Researchers have also demonstrated that patients considered obese are more susceptible to need treatment for CVD than lean patients (26). One advantage of the system designed by Valavanis and colleagues (2008) is that the precocious detection of weight gain could allow a preventive intervention by modifying lifestyle and decreasing obesity related diseases and thus minimizing governmental costs $(25,26)$.

Resting energy expenditure (REE) determination is largely important in the treatment of obese patients to the adequate dietary prescription, as it contributes from 50 to $75 \%$ to total energy expenditure. The gold standards for REE are Indirect Calorimetry and Doubly Labeled Water (DLW), however it demands expensive equipments and the need of trained staff, limiting the routine clinical practice. Predictive equations of REE can be applied as a convenient and less expensive alternative, although have some limitations, like being unsuitable for predicting REE in patients with extreme BMI. Disse and colleagues (2016) aimed to developed an ANN model for predict REE in obesity instead of regular equations. The model demonstrated to be more precise and accurate when compared to 23 predictive REE equations in obese subjects (27). 
BMI is a measure that uses body mass in kilograms divided by the square of height in meters and the result is ranked in underweight till obese. This index could be inefficiently applied as a body fatness measure, however it does not include factors like age, sex, ethnicity, and muscle mass, providing a false diagnosis of body fatness $(28,29)$. So, several studies put in check the BMI reliability as an indicator of obesity. In this regard, Saddek and colleagues (2012) aimed to predict levels of obesity to guide physicians decision making by developing a fuzzy logic system. This approach is a useful tool to manage dichotomous problems in circumstances with complex or insufficient data. Ten inputs variables, such as genetic influence, negative emotions, and food culture were added to the system in order to refine BMI results. As a result, this system may be effectively used as part of a therapy to improve welfare and minimize morbimortality (30).

Eating behavior is defined as "thoughts, actions, and intents that an organism enacts in order to ingest solids or liquids" (26) that could be better understood with the study of the personality traits of each person (31). A major challenge in obesity is to monitor the individual food/caloric intake (32). The most used method nowadays is a self-reported dietary questionnaire; however, it is an inaccurate method. The other widely used method is called DLW, a highly accurate methodology that cannot be applied to big samples, is expensive and does not provide details on eating patterns and meal contents. Due to these limitations, many efforts to develop a system that monitors individual food intake are being performed (32).

A system created by Sun and colleagues (2008) monitored individual intake based on pictures of food that are transmitted to a central responsible to give nutritional and caloric contents of the food portion in the photo. In this study, the researchers developed a calibration card used as a reference tool, in view of the importance of determining food volume. A high accuracy with errors between 5\% and 8\%. In addition, this system gives both qualitatively and quantitatively information regarding food intake (33).

A study conducted by Lopez-Meyer and colleagues (2010) used a Support Vector Machine to monitor feeding behavior in overweight people, according to their chews and swallows. The sample consisted of 18 subjects performing 4 experiments each one. Chews and swallows may be applied to differentiate periods of resting and eating with a fixed interval of 30 seconds. The results demonstrated that the model achieved an accuracy of $94 \%$ when the combination of chewing signals and information of swallowing sequences was measured, while information on swallows only resulted in an accuracy of $77 \%$. The perspective of this model is the application of this methodology in free living conditions, by controlling food intake, which could benefit patients with obesity and eating disorders (34).

In view of the specific food consumed information provided by tools that measure calorie intake, it could be positively applied with the DLW results, which are energy expenditure and calorie intake. By using support vector machine and image processing it was possible to contemplate all dimensions of eating behavior, which include emotional, external and restrained eating (31). Considering that the simultaneous use of both systems could lead to more consistent results, they could be considered synergistic $(33,34)$.

AI systems are very complex and hard to test, so build a system in the right way and for the right purpose requires non conventional tests of verification and validation methods, since they are not enough to prove the capacity of an AI software. Therefore, these AI systems requires more advanced formal methods for checking its reliability $(35,36)$. 


\section{Conclusions}

After analyzing the studies in this review, we observed that all investigated AI systems may have a tendency to more accurate results. Such finding can be well applied to health, as the lowest uncertainty in this area, the best the outcome. In the current century, AI efficacy has already been well established, becoming a routine. The growing applications of AI can be attributed to the easy access to technology. Thus, the development of new AI systems for treatment of diseases, especially obesity, could be a strategy to increase the adherence of subjects to these treatments.

\section{References}

1. Finucane MM, Stevens GA, Cowan MJ, Danaei G, Lin JK, Paciorek CJ, et al. National, regional, and global trends in body-mass index since 1980: systematic analysis of health examination surveys and epidemiological studies with 960 country-years and 9.1 million participants. Lancet 2011; 377(9765):557-67.

2. Monteiro CA, Conde WL, Popkin BM. Income-specific trends in obesity in Brazil: 1975-2003. American Journal of Public Health 2007; 97(10):1808-12.

3. Kelly T, Yang W, Chen CS, Reynolds K, He J. Global burden of obesity in 2005 and projections to 2030. International Journal of Obesity 2008; 32(9):1431-7.

4. Lavie CJ, Milani RV, Ventura HO. Obesity and cardiovascular disease: risk factor, paradox, and impact of weight loss. J Am Coll Cardiol 2009; 53(21):1925-32.

5. Ledley RS, Lusted LB. Reasoning Foundations of Medical Diagnosis. M D Computing 1991; $8(5): 300-15$.

6. Lisboa PJ. A review of evidence of health benefit from artificial neural networks in medical intervention. Neural Netw 2002; 15(1):11-39.

7. Russell SJ, Norvig P. Artificial Intelligence: A Modern Approach. $3^{\mathrm{a}}$ ed. USA: Pearson Education Inc.; 2010.

8. Haugeland, J. Artificial Intelligence: The Very Idea. MIT Press; 1985.

9. Rich, E, Knight, K. Artificial Intelligence. 2a ed. McGraw-Hill; 1991.

10. Kurzweil, R. The Age of Intelligent Machines. MIT Press; 1990.

11. Darcy AM, Louie AK, Roberts LW. Machine Learning and the Profession of Medicine. JAMA 2016; 315(6):551-2.

12. Jiang F, Jiang Y, Zhi H, Dong Y, Li H, Ma S, Wang Y, Dong Q, Shen H, Wang Y. Artificial intelligence in healthcare: past, present and future. Stroke and Vascular Neurology 2017; 0: e000101. doi:10.1136/svn-2017-000101.

13. Murff HJ, Fitz Henry F, Matheny ME, Gentry N, Kotter KL, Crimin K, Dittus RS, Rosen AK, Elkin $\mathrm{PL}$, et al. Automated identification of postoperative complications within an electronic medical record using natural language processing. JAMA 2011; 306:848-855.

14. Stefanelli M. The socio-organizational age of artificial intelligence in medicine. Artificial Intelligence in Medicine 2001; 23(1):25-47.

15. Menzies T, Pecheur C. Verification and Validation and Artificial Intelligence. Advances in Computers (Internet) 2005; 65:(153-201 pp.).

16. Cruz MR, Martins C, Dias J, Pinto JS. A validation of an intelligent decision-making support system for the nutrition diagnosis of bariatric surgery patients. JMIR Med Inform 2014; 2(2):e8.

17. Iacob Cl, Harrison R, Faily S. Online Reviews as First Class Artifacts in Mobile App Development. Lecture Notes of the Institute for Computer Sciences, Social Informatics and Telecommunications Engineering: Mobile Computing, Applications, and Services; 2014. p. 47-53.

18. App stores: number of apps in leading app stores (Internet). 2017. Available from: https://www.statista.com/statistics/276623/number-of-apps-available-in-leading-app-stores/.

19. Kranz M, Moeller A, Hammerla N, Diewald S, Ploetz T, Olivier P, et al. The mobile fitness coach: 
Towards individualized skill assessment using personalized mobile devices. Pervasive and Mobile Computing 2013; 9(2):203-15.

20. Schoffman DE, Turner-McGrievy G, Jones SJ, Wilcox S. Mobile apps for pediatric obesity prevention and treatment, healthy eating, and physical activity promotion: just fun and games? Translational Behavioral Medicine 2013; 3(3):320-5.

21. Buttussi F, Chittaro L. MOPET: a context-aware and user-adaptive wearable system for fitness training. Artif Intell Med 2008; 42(2):153-63.

22. Keung C, Lee A, Lu S. BunnyBolt: a mobile fitness app for youth. Proceedings of the 12th International Conference on Interaction Design and Children; New York, NY, USA: ACM; 2013. p. 24-7.

23. Sweeney S. App-titude: Gather Around the Virtual Meeting Table. The ASHA Leader (Internet). 2013; 18:(34-5 pp.).

24. Goh G, Tan NC, Malhotra R, Padmanabhan U, Barbier S, Allen JC, et al. Short-term trajectories of use of a caloric-monitoring mobile phone app among patients with type 2 diabetes mellitus in a primary care setting. J Med Internet Res 2015; 17(2):e33.

25. Valavanis IK, Mougiakakou SG, Marinos S, Karkalis G, Grimaldi KA, Gill R, et al. Gene - Nutrition Interactions in the Onset of Obesity as Cardiovascular Disease Risk Factor based on a Computational Intelligence Method. 8th Ieee International Conference on Bioinformatics and Bioengineering, Vols 1 and 2. 2008:170-5.

26. Finkelstein EA, Trogdon JG, Brown DS, Allaire BT, Dellea PS, Kamal-Bahl SJ. The lifetime medical cost burden of overweight and obesity: implications for obesity prevention. Obesity (Silver Spring). 2008; 16(8):1843-8.

27. Disse E, Ledoux S, Bétry C, Caussy C, Maitrepierre C, Coupaye M, et al. An artificial neural network to predict resting energy expenditure in obesity. Clin Nutr 2017.

28. Heo M, Faith MS, Pietrobelli A, Heymsfield SB. Percentage of body fat cutoffs by sex, age, and race-ethnicity in the US adult population from NHANES 1999-2004. Am J Clin Nutr 2012; 95(3):594-602.

29. Shah NR, Braverman ER. Measuring adiposity in patients: the utility of body mass index (BMI), percent body fat, and leptin. PLoS One 2012; 7(4):e33308.

30. Saddek B, Bounechada M, Djoudi A, Harzallah D, Alleg F, Benamrani H. Prevention of Obesity using Artificial Intelligence Techniques. International Journal of Science and Engineering Investigations 2012; 1(9):146-50.

31. Elfhag K, Morey LC. Personality traits and eating behavior in the obese: poor self-control in emotional and external eating but personality assets in restrained eating. Eat Behav 2008; 9(3):285-93.

32. Leung AWY, Chan RSM, Sea MMM, Woo J. An Overview of Factors Associated with Adherence to Lifestyle Modification Programs for Weight Management in Adults. Int J Environ Res Public Health 2017;14(8).

33. Sun M, Liu Q, Schmidt K, Yang J, Yao N, Fernstrom JD, et al., editors. Determination of Food Portion Size by Image Processing. 30th Annual International Conference of the IEEE-Engineeringin-Medicine-and-Biology-Society; 2008, Aug 20-24; Vancouver, CANADA 2008.

34. Lopez-Meyer P, Schuckers S, Makeyev O, Sazonov E. Detection of periods of food intake using Support Vector Machines. Conf Proc IEEE Eng Med Biol Soc 2010; 1004-7.

35. Preece A. Evaluating Verification and Validation Methods in Knowledge Engineering Industrial Knowledge Management (Internet). 2001:(91-104 pp.).

36. Menzies T, Pecheur C. Verification and Validation and Artificial Intelligence. Advances in Computers 2005; 65:153-201. 